\title{
Doctor of Philosophy in Human Services
}

National Cancer Institute

\section{Source}

National Cancer Institute. Doctor of Philosophy in Human Services. NCI Thesaurus. Code C39388.

The Doctor of Philosophy in Human Services is a postgraduate degree in areas of specialization addressing social challenges within the health care field. 